\title{
BMJ Open Smoking susceptibility among non- smoking school-going adolescents in Malaysia: findings from a national school-based survey
}

\author{
Kuang Hock Lim, ${ }^{1}$ Sumarni Mohd Ghazali, ${ }^{1}$ Hui Li Lim, ${ }^{2}$ Kee Chee Cheong, ${ }^{1}$ \\ Chien Huey Teh, ${ }^{1}$ Kuang Kuay Lim, ${ }^{3}$ Pei Pei Heng, ${ }^{1}$ Yong Kang Cheah, ${ }^{4}$ \\ Jia Hui Lim ${ }^{5}$
}

To cite: Lim KH, Ghazali SM, Lim HL, et al. Smoking susceptibility among nonsmoking school-going adolescents in Malaysia: findings from a national schoolbased survey. BMJ Open 2019;9:e031164. doi:10.1136/ bmjopen-2019-031164

- Prepublication history for this paper is available online. To view these files, please visit the journal online (http://dx.doi org/10.1136/bmjopen-2019031164).

Received 24 April 2019 Revised 27 September 2019 Accepted 08 October 2019

D Check for updates

(c) Author(s) (or their employer(s)) 2019. Re-use permitted under CC BY-NC. No commercial re-use. See rights and permissions. Published by BMJ.

${ }^{1}$ Special Resource Center, Institute for Medical Research, Kuala Lumpur, Malaysia

${ }^{2}$ Pathology Unit, Hospital Sultan Haji Ahmad Shah, Mentakab, Malaysia

${ }^{3}$ Occupational Health Center, Institute of Public Health, Setia Alam, Malaysia

${ }^{4}$ College of Business, Universiti Utara Malaysia, Sintok, Malaysia

${ }^{5}$ School of Pharmacy, Monash University, Malaysia Campus, Bandar Sunway, Malaysia

Correspondence to Dr Kuang Hock Lim; keelimkota@yahoo.com

\section{ABSTRACT}

Objective The identification of susceptible non-smoking adolescents is an essential step in reducing smoking initiation among adolescents. The aim of this study was to examine the prevalence and factors associated with smoking susceptibility among non-smoking school-going adolescents in Malaysia.

Design Cross-sectional study.

Setting Primary and secondary schools in Malaysia.

Participants 11246 non-smoking school-going adolescents.

Outcome measures The prevalence and factors associated with smoking susceptibility among nonsmoking school-going adolescents in Malaysia. Results Approximately $14 \%$ of non-smokers were susceptible to smoking, and the prevalence of susceptibility was significantly higher among males, eversmokers and e-cigarette users. The odds of susceptibility to smoking were higher among males, e-cigarette users, those aged 12 years and under and those who had ever smoked or tried cigarettes. Students from schools with educational programmes on the health effects of secondhand smoke (SHS) and who perceived smoking to be harmful were less likely to be susceptible to smoking. Conclusion Smoking susceptibility is prevalent among school-going adolescents. A comprehensive approach that enhances or reinforces health education programmes on the adverse health effects of smoking and SHS among school children, that considers multiple factors and that involves all stakeholders is urgently needed to reduce the prevalence of smoking susceptibility among vulnerable subgroups, as identified from the present findings.

\section{INTRODUCTION}

Malaysian burden of disease and mortality statistics show that smoking-related diseases contribute significantly to the burden of diseases $^{1}$ and are among the major causes of premature death in the Malaysian population. ${ }^{2}$ Thus, reduction of smoking prevalence among current smokers and smoking initiation among non-smokers are among the measures to be implemented. ${ }^{3}$ Most smokers
Strengths and limitations of this study

- The findings can be generalised to school-going adolescents attending government schools in Malaysia, which comprises the majority of the Malaysian adolescent population.

- Anonymity of the information gathered from the respondents might have reduced under- or over-reporting of smoking status and smoking susceptibility status.

- Only school-going adolescents in government schools were included in the study; those studying in private schools and those not in school were not included in this study.

- Objective measurement of smoking among non-smoking adolescents (eg, measurement of carbon monoxide in expired air or serum cotinine, a nicotine metabolite) was not carried out.

initiate smoking as adolescents. ${ }^{45}$ The likelihood of adolescents who do not smoke to become smokers as adults is low and vice versa. ${ }^{67}$ A Malaysian study revealed $80 \%$ of adult smokers began to smoke before the age of 20 years. ${ }^{8}$ Those who initiate smoking at younger ages are at greater risk of smoking-related diseases ${ }^{9} 10$ since they are more likely to become habitual smokers later in adulthood. Therefore, the identification of non-smoking adolescents with the possibility to initiate smoking is a prerequisite to reduce smoking initiation among youths.

Susceptibility to smoking (SS) or the lack of a cognitive commitment to refrain from future smoking which was introduced by Pierce et $a l^{11}$ has been recognised as a valid and reliable tool to identify non-smoking adolescents who are at risk of initiating smoking. ${ }^{12-14}$ The conceptual validity of the SS spurred the conduct of various studies to identify factors associated with smoking 
susceptibility among adolescents. Multiple intrapersonal and interpersonal factors were identified such as male sex, ${ }^{1516}$ older age,${ }^{16}{ }^{17}$ having had either smoking parents or peers, ${ }^{17-21}$ being exposed to second-hand smoke (SHS) at home or outside home ${ }^{151819}$ and receiving tobacco industry promotions. ${ }^{1521}$ Never-smoking youths who received anti-smoking education and had better knowledge of the harms of smoking and SHS were significantly associated with decreased smoking susceptibility. ${ }^{15161921}$ In contrast, adolescents who never smoked and were somehow exposed to tobacco promotions on mass media were significantly associated with increased smoking susceptibility. ${ }^{22}$

Local studies, among a representative samples of secondary school-going adolescents in Malaysia, ${ }^{23} 24$ reported that being male, poor academic achievement, ever-smoking, having smoking parents or peers, and high levels of stress, anxiety and depression were significantly associated with smoking susceptibility. However, as those studies were conducted in 2009 and 2012, the findings generated might not reflect the current scenario of 'smoking susceptibility' among Malaysian youth. Many new tobacco control policies and legislations have been introduced since 2011, including the expansion of smoke-free areas, ${ }^{25-27}$ increasing the price of cigarettes, ${ }^{28}$ community interventions focusing on 'smoke free homes ${ }^{29}$ and the introduction of e-cigarettes in the market ${ }^{30}$ which might conceivably change the prevalence of smoking susceptibility among adolescents and its associated factors.

Furthermore, several variables that have been shown to be associated with SS, such as exposure to SHS, ${ }^{15} 1718$ knowledge on the health hazards of smoking, ${ }^{15} 16192131$ exposure to tobacco advertisements, ${ }^{22}$ exposure to antismoking messages and being ever smokers and e-cigarette users, ${ }^{17} 203233$ were not investigated in previous local studies. Therefore, this paper aims to describe the prevalence of smoking susceptibility, along with its associated factors, among non-smoking upper-primary and secondary school-going adolescents utilising data from the most recent national survey, the Malaysian Tobacco and E-cigarette Survey 2016.

\section{METHODOLOGY \\ Sampling}

The Tobacco and E-Cigarette Survey among Malaysian adolescents was conducted in 2016. It employed multistage cluster sampling to select a representative sample of upper primary and secondary school students based on an updated sampling frame from the Ministry of Education Malaysia. Malaysia was first stratified into 15 states and then by the urban status of the schools. Schools that formed the primary sampling units were selected by systematic probability sampling proportionate to student enrolment. The second stage was the selection of classes from the selected schools using simple random sampling, and all students from the selected classes were invited to participate in the study. The sample size was determined by a single proportion formula based on a prevalence of $3 \%$, a margin of error of 1.5 , a design effect of 1.5 and an expected non-response rate of $20 \%$. A total of 13980 students from 138 schools were finally recruited for the survey.

\section{Instrument and measures}

The questionnaire used was adopted from the Youth Risk Behaviour Survey, ${ }^{34}$ which was translated and pretested to establish face validity prior to use in the actual survey. Only respondents who had obtained written consent from their parents/guardians were allowed to participate in the study. The objective and scope of this study, as well as the confidentiality of all information provided, were fully explained to the students prior to data collection. The respondents had the right not to answer any item in the questionnaire. In addition, the details of the items in the questionnaire were also explained by the research team members.

Only non-smokers (respondents who answered 'not at all' to the item 'Have you smoked during the last 30 days') were included in the analysis. The dependent variable was susceptible to smoking, which was measured by the following two items: (a) Do you think you will smoke a cigarette in the next year? and (b) If one of your best friends were to offer you a cigarette, would you smoke? The choices of answers were (a) 'Definitely not', (b) 'Probably not', (c) 'Probably yes' and (d) 'Definitely yes'. Respondents who answered 'Definitely not' to both items were categorised as non-susceptible to smoking, while those who chose other combinations were classified as susceptible to smoking.

The independent variable was SHS exposure at home and places other than home, which was measured by the following questions: (a) 'In the last seven days, did anyone smoke at your home in your presence?' and (b) 'In the last sevendays, did anyone smoke other than in your home in your presence?' Respondents who answered '0 days' were categorised as not exposed to SHS, whereas those who answered ' $1-2$ days' ' '3-4 days', '5-6 days' and 'all seven days' were categorised as exposed to SHS. Other variables measured were social demographic factors (sex, age group, schooling area, ethnicity), knowledge of the harmful effects of smoking (yes/no), current e-cigarette (ECV) user (Yes/No), had been taught in school about the harmful effects of smoking (yes/no), ever seen antismoking in the media (yes/no), ever seen someone smoking in a movie (yes/no) and perceived smoking as enjoyable (yes/no).

\section{Data management and analysis}

The data were cleaned and weighted based on the study design and response rate using the latest population census data prior to analysis. The social demographic characteristics of the respondents were described in frequencies and percentages. Univariate analyses with $p$ values less than or equal to 0.25 were included in the 
multiple logistic regression to determine the association between all independent variables and smoking susceptibility among non-smokers after adjusting for the confounding effects. Two-way interaction analyses were carried out among all independent variables. A $p$ value above 0.05 indicated no significant two-way interaction between the independent variables. All statistical analyses were carried out using the complex sample design of Statistical Product and Serve Solutions (SPSS) statistical software V.22 at an alpha level of 5\%.

\section{Patient and public involvement}

Neither patients nor the public were involved in the formulation of research questions and outcome measures, decisions regarding study design, recruitment or conduct of this study. Study findings in the form of a technical report were disseminated to relevant stakeholders and the public but not specifically to the respondents.

\section{RESULTS}

A total of 13162 adolescents responded to the survey for a response rate of $94.1 \%$. Among the respondents, 11246 $(\mathrm{n}=85.4 \%)$ were non-cigarette smokers. The proportion of non-smokers was significantly higher among female respondents ( 97.9 vs $78.9, \mathrm{p}<0.001)$, those who resided in an urban area $(92.1 \%$ vs $85.1 \%, \mathrm{p}<0.001)$, those who were aged 12 years and below (94.2\% vs $85.2 \%$ in $13-16$ years and $84.3 \%$ in $16-19$ years, $\mathrm{p}<0.001)$ and those who were of Chinese descent (96.8\%) (table 1). Only respondents who were non-smokers were included in the analysis.

The prevalence of SS was $13.9 \%$ (table 2). The proportion of respondents who were susceptible to smoking was almost six times higher among current e-cigarette users and approximately two times higher among males, ever smokers, those who perceived smoking as enjoyable and not harmful and those who had never been taught about the harmful effects of smoking. In addition, those who had never seen anti-tobacco advertisements, in the youngest age group (12 years and below), and those who have ever been exposed to SHS at places other than the home were also found to have higher SS.

In multivariable regression analysis, SS was significantly higher among ECV users (adjusted OR (AOR): 5.12, 95\% CI 3.67 to 7.14 ), respondents who perceived smoking as enjoyable (AOR: 2.90, 95\% CI 2.04 to 4.12 ) and ever smokers (AOR: 2.46, 95\% CI 1.93 to 3.12), whereas those who were female, had been taught in school about the dangers of smoking, perceived smoking as harmful to health, never seen others smoking in school and not exposed to SHS at places other than at home were less susceptible to smoking (table 3 ).

\section{DISCUSSION}

The prevalence of SS among non-smoking, school-going adolescents was $13.9 \%$. This finding is comparable to the $12 \%$ prevalence reported in Pakistan ${ }^{19}$ and $12.5 \%$

Table 1 Sociodemographic characteristics of respondents

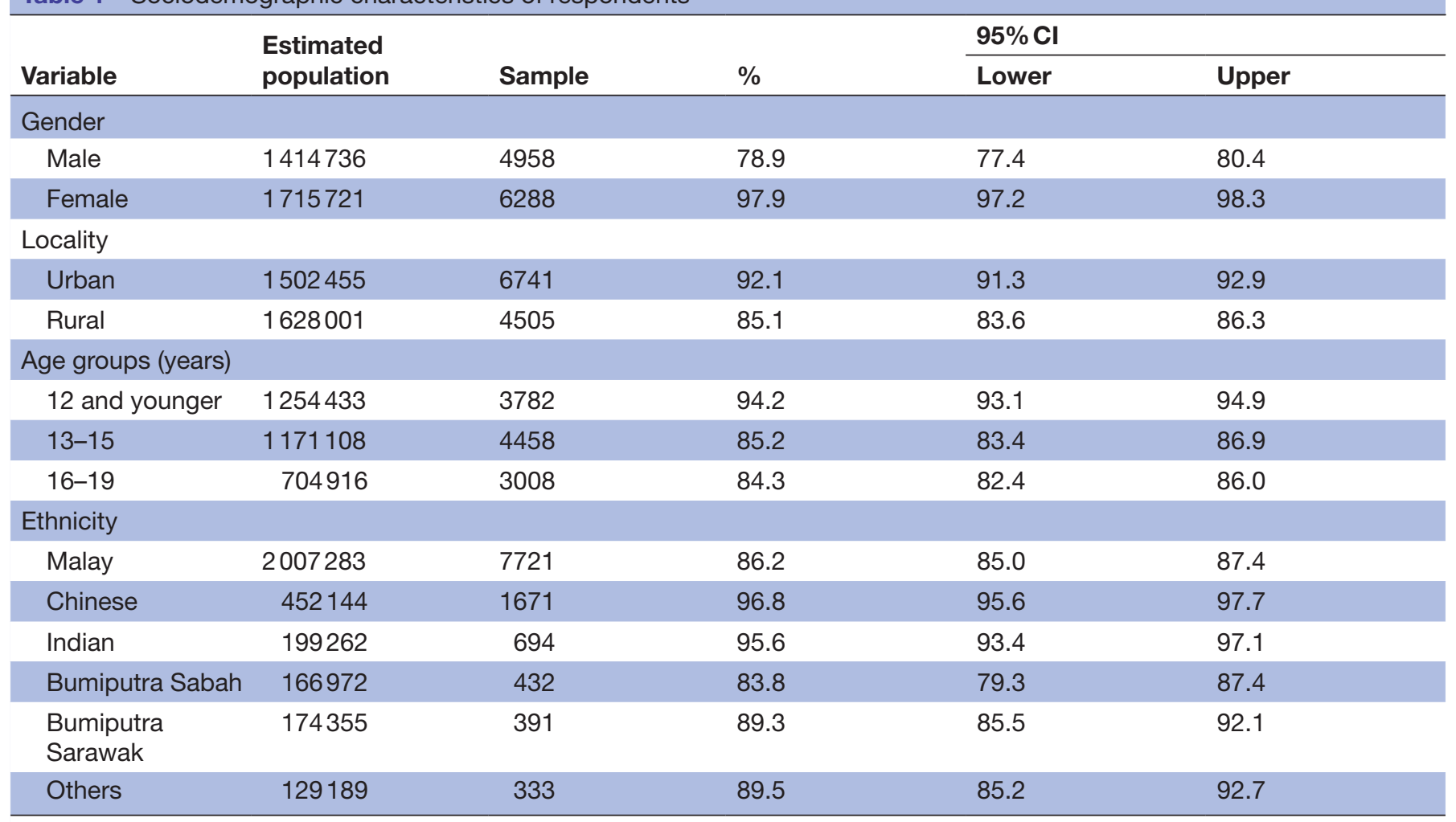


Open access

Table 2 Susceptibility to smoking among non-smoking adolescent students in Malaysia

\section{Smoking susceptibility}

\begin{tabular}{|c|c|c|c|c|c|c|}
\hline \multirow[b]{2}{*}{ Variable } & \multirow{2}{*}{$\begin{array}{l}\text { Estimated } \\
\text { population }\end{array}$} & \multirow[b]{2}{*}{ Sample } & \multirow[b]{2}{*}{$\%$} & \multicolumn{2}{|l|}{$95 \% \mathrm{Cl}$} & \multirow[b]{2}{*}{$P$ value } \\
\hline & & & & Lower & Upper & \\
\hline Overall & 436132 & 1557 & 13.9 & 13.0 & 14.9 & \\
\hline \multicolumn{7}{|l|}{ Sex } \\
\hline Male & 278314 & 954 & 19.7 & 18.1 & 21.3 & $<0.001$ \\
\hline Female & 157818 & 603 & 9.2 & 8.3 & 10.2 & \\
\hline \multicolumn{7}{|l|}{ Locality } \\
\hline Urban & 196149 & 875 & 13.1 & 11.9 & 14.3 & 0.069 \\
\hline Rural & 239983 & 682 & 14.7 & 13.4 & 16.2 & \\
\hline \multicolumn{7}{|l|}{ Age groups (years) } \\
\hline 12 and younger & 188376 & 608 & 15.0 & 13.7 & 16.5 & 0.092 \\
\hline $13-15$ & 160607 & 560 & 13.7 & 12.1 & 15.5 & \\
\hline $16-19$ & 87149 & 389 & 12.4 & 10.7 & 14.2 & \\
\hline \multicolumn{7}{|l|}{ Ethnicity } \\
\hline Malay & 279189 & 1056 & 13.9 & 12.7 & 15.2 & $<0.001$ \\
\hline Chinese & 46953 & 173 & 10.4 & 8.7 & 12.3 & \\
\hline Indian & 42769 & 143 & 9.8 & 8.2 & 11.7 & \\
\hline Bumiputra Sabah & 23118 & 62 & 13.8 & 10.4 & 18.1 & \\
\hline Bumiputra Sarawak & 25252 & 53 & 14.5 & 11.0 & 18.8 & \\
\hline Others & 18849 & 64 & 14.6 & 11.0 & 19.1 & \\
\hline \multicolumn{7}{|c|}{ SHS exposure in the house } \\
\hline Yes & 161095 & 566 & 15.3 & 13.7 & 17.1 & 0.038 \\
\hline No & 274619 & 990 & 13.2 & 12.2 & 14.4 & \\
\hline \multicolumn{7}{|c|}{ SHS exposure other than in the house } \\
\hline Yes & 226210 & 823 & 15.4 & 14.0 & 17.0 & 0.003 \\
\hline No & 209922 & 734 & 12.6 & 11.5 & 13.8 & \\
\hline \multicolumn{7}{|l|}{ Ever smoker } \\
\hline Yes & 40451 & 174 & 36.1 & 29.8 & 42.9 & $<0.001$ \\
\hline No & 394810 & 1381 & 13.1 & 12.2 & 14.0 & \\
\hline \multicolumn{7}{|l|}{ E-cigarette user } \\
\hline Yes & 20333 & 87 & 65.2 & 52.2 & 76.3 & $<0.001$ \\
\hline No & 331270 & 1188 & 11.8 & 10.9 & 12.7 & \\
\hline \multicolumn{7}{|c|}{ Ever been taught in school about the harms of smoking } \\
\hline Yes & 287006 & 1002 & 12.0 & 11.1 & 13.1 & $<0.001$ \\
\hline No & 86830 & 319 & 21.4 & 18.7 & 24.2 & \\
\hline \multicolumn{7}{|c|}{ Tobacco smoke is harmful } \\
\hline Yes & 359019 & 1278 & 12.7 & 11.8 & 13.7 & $<0.001$ \\
\hline No & 7714 & 279 & 24.6 & 21.5 & 27.9 & \\
\hline \multicolumn{7}{|c|}{ Ever seen anti-tobacco messages } \\
\hline Yes & 384619 & 1284 & 13.4 & 12.5 & 14.4 & 0.004 \\
\hline No & 70645 & 268 & 17.2 & 14.7 & 20.0 & \\
\hline \multicolumn{7}{|c|}{ Ever seen someone smoke during a movie } \\
\hline Yes & 313269 & 1107 & 13.0 & 12.0 & 14.1 & 0.062 \\
\hline No & 98986 & 366 & 15.1 & 13.3 & 17.1 & \\
\hline
\end{tabular}

Continued 


\begin{tabular}{|c|c|c|c|c|c|c|}
\hline \multirow[b]{3}{*}{ Variable } & \multicolumn{6}{|c|}{ Smoking susceptibility } \\
\hline & \multirow{2}{*}{$\begin{array}{l}\text { Estimated } \\
\text { population }\end{array}$} & \multirow[b]{2}{*}{ Sample } & \multirow[b]{2}{*}{$\%$} & \multicolumn{2}{|l|}{$95 \% \mathrm{CI}$} & \multirow[b]{2}{*}{$P$ value } \\
\hline & & & & Lower & Upper & \\
\hline Yes, not attractive & 145563 & 560 & 13.3 & 11.9 & 14.9 & \\
\hline Yes, very attractive & 24398 & 95 & 38.7 & 31.1 & 46.8 & \\
\hline Yes & 22979 & 74 & 32.3 & 24.3 & 41.5 & $<0.001$ \\
\hline No & 412400 & 1478 & 13.5 & 12.6 & 14.5 & \\
\hline
\end{tabular}

SHS, second-hand smoke.

prevalence from a worldwide study. ${ }^{15}$ Our prevalence was slightly lower than figures from Ethiopia $(16.9 \%)^{31}$ and Poland $(22 \%)^{17}$ but slightly higher than those reported in Thailand $(7.4 \%)^{35}$ and Taiwan $(11 \%) .{ }^{18}$ These differences are presumably due to social and cultural variation across countries. In Asian countries, female smoking is perceived as unfeminine, but not in Western countries. ${ }^{5}$ Furthermore, the influence of the tobacco industry, tobacco control legislation and tobacco prevention measures in each country such as differences in smokefree areas between countries, level of indexation of tobacco products, packaging requirements of tobacco products, direct and indirect advertisement and promotion of tobacco products may also contribute to the disparity. In addition, differences in the age range of respondents between the current study (11-18 years old) and the studies in Thailand, Pakistan and Taiwan (13-15 years old), ${ }^{18} 1935$ definition of non-smoking (never/ever smokers) and the study localities (different definitions of urban and rural areas) ${ }^{36} 37$ may have a bearing on the prevalence of susceptibility.

The prevalence of smoking susceptibility in this study was two times higher than the 2012 rate among schoolgoing adolescents in Malaysia. ${ }^{24}$ This finding was unexpected given the tobacco control measures that have been implemented by the Ministry of Health in the last 5 years, such as increasing the prices of tobacco products $^{27}$ and health promotion activities targeting schoolgoing adolescents. Therefore, comprehensive and in-depth studies are strongly recommended to elucidate the factors that contribute to the large increase in smoking susceptibility among Malaysian youth. Our study revealed that male adolescents were more susceptible to smoking. This finding might be due to two reasons. First, smoking among males is a norm accepted by Malaysian society, and second, higher smoking prevalence among male adults who serve as role models for male adolescents may initiate smoking. ${ }^{24}$

The odds of smoking susceptibility were increased fivefold among ECV users compared with non-ECV users. This finding is consistent with a study reported by Azagba et al in Canada, ${ }^{20}$ in which the odds of SS among ECV users was 2.02 (95\% CI 1.43 to 2.84) after adjusting for sex, grade level, region of residence, smoking-related exposure and school-level area. Similar findings have also been demonstrated by numerous studies in the USA. ${ }^{33} 3839$ The National Youth Tobacco Survey, which targeted middle and high school students in the USA in 2014, revealed that among non-smokers, ever use of e-cigarettes was significantly associated with intention to smoke cigarettes. ${ }^{32}$ Extensive marketing of e-cigarettes as a safer alternative to cigarettes, which primarily targeted adolescents, has resulted in the social denormalisation of cigarette smoking. ${ }^{40}$ The Malaysian anti-tobacco legislation to date has no provision that prohibits the advertisement of ECV without nicotine liquid. ${ }^{28}$ This might contribute to normalising e-cigarette use, which ultimately re-normalised smoking behaviours. In addition, non-smokers who use e-cigarettes containing nicotine might have enhanced nicotine-induced rewards such as mild euphoria and cognitive function enhancement, thus increasing smoking susceptibility. ${ }^{41}$ Our results are also consistent with the hypothesis that e-cigarettes may act as a mediator for subsequent cigarette consumption ${ }^{42} 43$ through either a pharmacologic pathway, a social re-normalisation mechanism, or both. Although the proportion of e-cigarette users who had ever used cigarettes appears to be small (4\%), it actually represents an estimated population of 114350 adolescents.

SHS exposure at places other than the home was significantly associated with SS (higher odds of being susceptible among the exposed); however, SHS exposure at home was not. Our findings contradicts with studies in selected African countries that observed higher odds (AOR: 1.3-3.2) between SHS exposure at home and SS. ${ }^{44}$ The worldwide study by Veeranki et $a l^{15}$ also reported significantly higher odds of SS among those with SHS exposure at home and in places other than the home. ${ }^{15}$ SHS exposure at home typically originates from smoking parents or household members. Previous studies have shown a significant association between smoking among household members and smoking initiation among adolescents. ${ }^{15} 2145$ Our contradictory results are best explained by the age difference of the study population, 


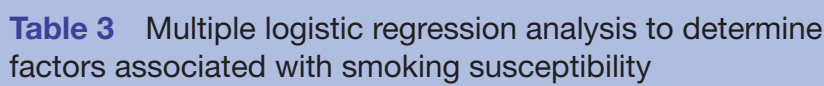
factors associated with smoking susceptibility

\begin{tabular}{|c|c|c|c|}
\hline \multirow[b]{2}{*}{ Variable } & \multirow[b]{2}{*}{ AOR } & \multicolumn{2}{|l|}{$95 \% \mathrm{Cl}$} \\
\hline & & Lower & Upper \\
\hline \multicolumn{4}{|l|}{ Sex } \\
\hline Male & 1.49 & 1.23 & 1.81 \\
\hline Female & Ref & & \\
\hline \multicolumn{4}{|l|}{ Locality } \\
\hline Urban & Ref & & \\
\hline Rural & 1.21 & 1.01 & 1.45 \\
\hline \multicolumn{4}{|c|}{ Age groups (years) } \\
\hline 12 and younger & 1.55 & 1.22 & 1.97 \\
\hline $13-15$ & 1.11 & 0.85 & 1.43 \\
\hline $16-19$ & Ref & & \\
\hline \multicolumn{4}{|l|}{ Ethnicity } \\
\hline Malay & 1.18 & 0.90 & 1.56 \\
\hline Chinese & Ref & & \\
\hline Indian & 2.03 & 1.41 & 2.92 \\
\hline $\begin{array}{l}\text { Bumiputra } \\
\text { Sabah }\end{array}$ & 1.34 & 0.84 & 2.14 \\
\hline $\begin{array}{l}\text { Bumiputra } \\
\text { Sarawak }\end{array}$ & 1.09 & 0.68 & 1.77 \\
\hline Others & 1.32 & 0.86 & 2.06 \\
\hline \multicolumn{4}{|c|}{ SHS exposure in the house } \\
\hline Yes & 0.99 & 0.80 & 1.25 \\
\hline No & Ref & & \\
\hline \multicolumn{4}{|c|}{ SHS exposure other than in the house } \\
\hline Yes & 1.31 & 1.05 & 1.63 \\
\hline No & Ref & & \\
\hline \multicolumn{4}{|l|}{ Ever smoker } \\
\hline Yes & 2.46 & 1.93 & 3.12 \\
\hline No & Ref & & \\
\hline \multicolumn{4}{|l|}{ E-cigarette user } \\
\hline Yes & 5.12 & 3.67 & 7.14 \\
\hline No & ref & & \\
\hline
\end{tabular}

Been taught in school about the harmful effects of tobacco

$\begin{array}{cccc}\text { Yes } & \text { Ref } & & \\ \text { No } & 1.71 & 1.40 & 2.08 \\ \text { Tobacco smoke is harmful } & & \\ \text { Yes } & \text { Ref } & & \\ \text { No } & 1.48 & 1.13 & 1.95\end{array}$

Ever seen anti-tobacco messages

$\begin{array}{llll}\text { Yes } & \text { Ref } & & \\ \text { No } & 0.93 & 0.70 & 1.24\end{array}$

Ever seen someone smoke during a movie

\begin{tabular}{cccc} 
Yes & 0.90 & 0.73 & 1.11 \\
No & Ref & & \\
Points of sale & & & \\
\hline
\end{tabular}

Continued
Table 3 Continued

\begin{tabular}{llll}
\hline & & $95 \% \mathbf{C l}$ & \\
Variable & AOR & Lower & Upper \\
\hline No & ref & & \\
$\begin{array}{l}\text { Yes, not } \\
\text { attractive }\end{array}$ & 0.93 & 0.76 & 1.14 \\
$\begin{array}{l}\text { Yes, very } \\
\text { attractive }\end{array}$ & 2.57 & 1.73 & 3.83 \\
$\begin{array}{l}\text { Seen someone smoking in school } \\
\text { Yes }\end{array}$ & 1.34 & \\
No & Ref & \\
Seen someone smoking outside the school & \\
Yes & 0.85 & 0.69 & 1.67 \\
No & Ref & & \\
\hline
\end{tabular}

Perceive smoking as enjoyable

$\begin{array}{llll}\text { Yes } & 2.90 & 2.04 & 4.12 \\ \text { No } & \text { Ref } & & \end{array}$

AOR, adjusted odds ratio; SHS, second-hand smoke.

as Lee $e t a l^{44}$ and Veeranki et $a l^{15}$ only investigated 13to 15-year-old adolescents, while this study examined respondents in the age range of 10-19 years. The influence of parental and household smoking varies by age, and according to human development theory, ${ }^{46}$ the influence of family members (parents/guardians, brothers or sisters) on adolescents aged 16-17 years is less strong than on those aged 13-15 years. However, the influence of family members on 10-12 year-old adolescents is similar to the influence on adolescents aged $13-15$ years. In addition, at home non-smoking female household members, especially the mother, may influence non-smoking adolescents to abstain from smoking. In contrast, outside of the home, there is no such influence, giving the impression that smoking is a norm accepted by the public. SHS contains 70 known carcinogens and poses a serious health impact on children. ${ }^{47}$ This finding therefore supports the need to expand smoke-free zones to more public areas in Malaysia.

Numerous studies have reported that the odds of SS increases with age. ${ }^{178}$ Our results, however, showed an inverse relationship between adolescents' age and SS, which is in line with a study by Aslam et al among adolescents in Pakistan. ${ }^{19}$ This phenomenon may be due to differences in the sociocultural environments across countries and may be an indication of the extent of youth-centred tobacco industry marketing or tobacco control measures. The unremarkable difference in the odds of SS between respondents aged 13-15 and those aged 16 years and above was in line with another local study among secondary school students. ${ }^{23}$ The higher odds of smoking susceptibility among students aged 12 years and below compared with those aged 16 years and above might be explained by human development 
theory. Cognitive development is accelerated during early adolescence; personal fables exhibited during adolescence induces feelings of omnipotence and of people around them eagerly watching or listening to them. As a result, this sense of invincibility makes young adolescents easily influenced by their surroundings and might even drive them to attempt smoking. ${ }^{46}$ In addition, this survey respondents aged 16 and above were those who continued schooling after taking a major public school examination at age 15 years in Malaysia. The adolescents who have not dropped out of school may be less likely to be involved in high-risk activities, especially smoking.

The odds of SS among ever-smokers were double the odds of those who had never smoked, which is in line with a study in Poland. ${ }^{1749}$ It has been observed that the former habits may influence future behaviour. Another plausible reason is that former smokers have more smoking peers that they used to smoke with, ${ }^{50}$ as well as lack of awareness of the adverse health consequences of smoking, ${ }^{50}$ hence their more positive disposition towards smoking.

The likelihood of SS was significantly higher among those who had ever encountered cigarette promotions at points of sale (PoS) and who found those advertisements attractive. Spanopoulos et $a l^{51}$ also revealed that adolescents who saw advertisements at PoS during store visits had more than threefold increased odds of smoking susceptibility (OR $3.15,95 \%$ CI 1.52 to 6.54 ). In addition, a systematic review by Paynter $e t a l,{ }^{52}$ which included 12 peer review studies, concluded that exposure to tobacco advertisements at PoS increased the likelihood of SS, as such exposure increased the perceived attractiveness of smoking and brand awareness. PoS tobacco marketing is designed to increase memorability through the mechanism of the mere exposure effect based on the limited amount of cognitive resources for perceiving, comprehending and remembering the information that the individual encounters in their environment. ${ }^{53}$ Both the direct (exposed cigarettes) and indirect (brand image) visual smoking cues, as well as related content such as tagline, commercial message and health warnings, help boost the memory of the tobacco products in the exposed population. Furthermore, the high visibility of tobacco advertisement supports a norm in which purchasing and using tobacco is accepted and therefore has the tendency to normalise smoking behaviours. ${ }^{545}$

In contrast to various findings that reported an association and causal relationship between smoking scenes in movies and smoking initiation among adolescents ${ }^{56}{ }^{57}$ as well as several human behavioural theories such as social learning theory ${ }^{58}$ and contextual effect theory, ${ }^{59}$ watching someone smoking might increase the likelihood of behavioural imitation followed by the instillation of a smoking-positive memory among viewers, which can influence future real-life behaviour. ${ }^{60}$ We did not find a significant association between being susceptible to smoking and watching someone smoking in a movie after adjusting for the confounding effect of other independent variables, which is in line with the finding by Polanska $e t a l^{17}$ which showed no significant association between seeing someone smoking in a movie with SS. In-depth qualitative studies are recommended to investigate the effect of smoking images in the media and SS among adolescents from different sociodemographic backgrounds. On the other hand, despite anti-smoking messages having been widely disseminated, we did not observe any significant protective effects of those messages on the non-smoking adolescent population. These results highlight a challenge for the public health and community health practitioners, in designing positive, instructive anti-smoking messages targeted to youth.

SS was 34\% higher among adolescents who had ever seen someone smoke in school, but no significant association was observed for ever seeing someone smoke outside of school with SS. This finding is in line with studies by Polanska $e t a l^{17}$ and Barnett $e t$ al. ${ }^{61}$ The people who may be seen smoking in school grounds may be teachers, other school staff or other students. Such behaviour in a teacher who is a role model might influence students' perception of smoking and therefore increase the likelihood of SS. However, future studies should include an item on the identity of the person seen smoking in school grounds.

Previous exposure in school to information on the health hazards of SHS was a protective factor against smoking susceptibility. The study showed that knowledge-based intervention does impact future health. This finding is congruent with findings among youth in Gambia, ${ }^{21} \mathrm{Nepa}^{62}$ and 168 LMIC countries, ${ }^{15}$ where the odds of SS were significantly higher among youth with poor knowledge on the harms of smoking.

Aryal and Batta ${ }^{63}$ reported an OR of smoking of 4.74 (95\% CI 2.58 to 8.72 ) among those who perceived smoking as enjoyable versus unenjoyable. Our study found that the odds of smoking susceptibility among non-smokers who perceived smoking as a pleasant feeling were almost three times higher than those who did not. This is in line with the decision balance component in the trans-theoretical model of change, as well as the theory of planned behaviour, ${ }^{64}$ in that positive perception is an integral component of behavioural change, and this also applies to smoking.

\section{Limitations of this study}

First, all estimates in our study were based on self-report, which might be affected by reporting bias. The practice of smoking or having the intention to smoke may not be socially acceptable. As a result, the report might also be affected by social desirability bias. The other limitation of our study is that our analysis did not control for other indicators that could be associated with smoking behaviour such as alcohol consumption, illicit drug use, parental and peers' smoking status and intrapersonal factors such as stress. Third, the cross-sectional study design limited the causal inferences between the dependent and independent variables. Despite the mentioned limitations, this study provides valuable insight into the 
prevalence and factors associated with SS among adolescents in Malaysia.

\section{CONCLUSIONS AND RECOMMENDATIONS}

The study findings indicate that a substantial proportion of Malaysian adolescents were susceptible to smoking, with higher odds among students aged 12 years and below, ECV users, ever smokers, students in rural schools and non-Malaysian students. Furthermore, a higher risk of smoking susceptibility was also observed among those who had ever seen someone smoking on school premises and were exposed to SHS at places other than the home. Lack of exposure in school to the harmful effects of tobacco and poor knowledge on the health impacts of SHS exposure were additional significant factors for SS initiation.

To overcome the threat of smoking susceptibility among Malaysian youths, sex- and culture-sensitive prevention programmes that focus on various social and behavioural aspects are needed. Schools and family institutions should actively promote tobacco-free living by declaring that tobacco consumption is not acceptable. All schools should incorporate a smoking intervention programme, such as integrating lectures on the health effects of smoking into the school syllabus, since this has been found to be an important preventive factor for smoking experimentation and initiation. ${ }^{65}$ In addition to school-based tobacco programmes, there is also a need for combined efforts at all levels. In addition to enforcement of the existing legislation, additional measures to decrease the social acceptance of smoking and creation of a non-smoking trend are imperative. A comprehensive approach based on building and supporting the protective factors among youths will reduce SS as well as other unhealthy behaviours. In conclusion, it is crucial to take into consideration the Malaysian sociocultural context in the design of tobacco control programmes to ensure their effectiveness in influencing adolescents' perceptions, reactions and behaviours towards smoking.

Acknowledgements We would like to thank the Director-General of Health, Malaysia, for his permission to publish this paper.

Contributors All authors were responsible and accountable to all part of works related to the study. More specifically, KHL, SMG, HLL, JHL and KCC contributed to the conception and design of this study. KKL, CHT, PPH and YKC were responsible for data acquisition and coordination of this study. KHL, SMG, PPH and KCC were involved in data management, performed statistical analysis and interpretation of the data. KHL, HLL, JHL and CHT contributed substantially to the writing and revising of the manuscript. All authors critically revised the manuscript and gave final approval to the version to be published.

Funding The project was funded by the Ministry of Health, Malaysia and Bloomberg Philanthropies.

Competing interests None declared.

Patient consent for publication Obtained.

Ethics approval The Medical Research Ethics Committee (MREC) of the Ministry of Health and the Ministry of Education, MREC evaluated and granted ethical approval for the study.

Provenance and peer review Not commissioned; externally peer reviewed.
Data availability statement No data are available.

Open access This is an open access article distributed in accordance with the Creative Commons Attribution Non Commercial (CC BY-NC 4.0) license, which permits others to distribute, remix, adapt, build upon this work non-commercially, and license their derivative works on different terms, provided the original work is properly cited, appropriate credit is given, any changes made indicated, and the use is non-commercial. See: http://creativecommons.org/licenses/by-nc/4.0/.

\section{REFERENCES}

1 Institute of Public Health, Ministry of Health Malaysia. Malaysian burden of disease and injury study, health prioritization: burden of disease approach, 2011.

2 Institute of Public Health. National Health \& Morbidity Survey 2015. Smoking among adults in Malaysia. Ministry of Health 2015.

3 Ministry of Health - National Strategic Plan on Tobacco Control 20152020. Strategic planning on smoking. Malaysia: Ministry of Health, 2014.

4 U.S. Department of Health and Human Services. Preventing tobacco use among youth and young adults: a report of the surgeon General; office on smoking and health, U.S. Atlanta, GA, USA: Department of Health and Human Services, Centers for Disease Control and Prevention, National Center for Chronic Disease Prevention and Health Promotion, 2012.

$5 \mathrm{Lim} \mathrm{KH}$, Lim HL, Teh $\mathrm{CH}$, et al. Smoking among school-going adolescents in selected secondary schools in Peninsular Malaysiafindings from the Malaysian adolescent health risk behaviour (MyaHRB) study. Tob Induc Dis 2017;15:9.

6 Hwang JH, Park S-W. Age at smoking initiation and subsequent smoking among Korean adolescent smokers. J Prev Med Public Health 2014;47:266-72.

7 Koprivnikar H, Korošec A. Age at smoking initiation in Slovenia. Zdrav Var 2015;54:274-81.

$8 \mathrm{Lim} \mathrm{K}$, Teh C, Pan S, et al. Prevalence and factor/s associated with smoking among adults in Malaysia - Findings from the National Health and Morbidity Survey (NHMS) 2015. Tob Induc Dis 2018;16:1-11.

9 Huxley RR, Yatsuya H, Lutsey PL, et al. Impact of age at smoking initiation, dosage, and time since quitting on cardiovascular disease in African Americans and whites: the Atherosclerosis risk in Communities study. Am J Epidemiol 2012;175:816-26.

10 Huxley RR, Woodward M. Cigarette smoking as a risk factor for coronary heart disease in women compared with men: a systematic review and meta-analysis of prospective cohort studies. The Lancet 2011;378:1297-305.

11 Pierce JP, Choi WS, Gilpin EA, et al. Validation of susceptibility as a predictor of which adolescents take up smoking in the United States. Health Psychology 1996;15:355-61.

12 Guindon GE, Georgiades K, Boyle MH. Susceptibility to smoking among South East Asian youth: a multilevel analysis. Tob Control 2008;17:190-7.

$13 \mathrm{Lim} \mathrm{KH}$, Sumarni MG, Kee CC, et al. Susceptible to smoking as a predictor of smoking initiation among adolescent in Malaysia- a longitudinal study in Kota Tinggi district, Malaysia. Medicine \& Health;6:49-58.

14 Carey FR, Wilkinson AV, Harrell MB, et al. Measurement and predictive value of susceptibility to cigarettes, e-cigarettes, cigars, and hookah among Texas adolescents. Addictive Behaviors Reports 2018;8:95-101.

15 Veeranki SP, Mamudu HM, Anderson JL, et al. Worldwide neversmoking youth susceptibility to smoking. Journal of Adolescent Health 2014;54:144-50.

16 Azagba S, Asbridge M. School connectedness and susceptibility to smoking among adolescents in Canada. Nicotine \& Tobacco Research 2013;15:1458-63.

17 Polańska K, Wojtysiak P, Bąk-Romaniszyn L, et al. Susceptibility to cigarette smoking among secondary and high school students from a socially disadvantaged rural area in Poland. Tob Induc Dis 2016;14:28.

18 Chen P-L, Huang W-G, Chao K-Y. Susceptibility to initiate smoking among junior and senior high school nonsmokers in Taiwan. Prev Med 2009;49:58-61.

19 Aslam S, Zaheer S, Rao S, et al. Prevalence and determinants of susceptibility to cigarette smoking among school students in Pakistan: secondary analysis of global youth tobacco survey. Subst Abuse Treat Prev Policy 2014;9:10.

20 Azagba S, Baskerville NB, Foley K. Susceptibility to cigarette smoking among middle and high school e-cigarette users in Canada. Prev Med 2017;103:14-19. 
21 Jallow IK, Britton J, Langley T. Prevalence and determinants of susceptibility to tobacco smoking among students in the Gambia. Nicotine Tob Res 2018:1-9.

22 Fulmer EB, Neilands TB, Dube SR, et al. Protobacco media exposure and youth susceptibility to smoking cigarettes, cigarette experimentation, and current tobacco use among US youth. PLOS One 2015;10:e0134734.

$23 \mathrm{Lim} \mathrm{KH}$, Sumarni MG, Kee CC, et al. Correlates of susceptibility to smoking among secondary school students in Kota Tinggi district, Johor, Malaysia. Asian Pac J Cancer Prev 2013;14:6971-8.

24 Lim KH, Chong Z, Khoo YY, et al. Parental smoking status, stress, anxiety, and depression are associated with susceptibility to smoking among non-smoking school adolescents in Malaysia. Asia Pac $J$ Public Health 2014;26:81S-90.

$25 \mathrm{Lim} \mathrm{KH}$, Teh $\mathrm{CH}$, Nik Mohamed MH, et al. Exposure to tobacco secondhand smoke and its associated factors among non-smoking adults in smoking-restricted and non-restricted areas: findings from a nationwide study in Malaysia. BMJ Open 2018;8:e017203.

26 Government of Malaysia. Declaration of non smoking area, 2012. Available: https://www.tobaccocontrollaws.org/files/live/Malaysia/ Malaysia\%20-\%20Dec.\%20of\%20Non-Smoking\%20Area\% 202012\%20-\%20national.pdf [Accessed 10 Mar 2019].

27 Government of Malaysia. Control of tobacco product (Amendment) regulation, 2015. Available: https://www.tobaccocontrollaws.org/ files/live/Malaysia/Malaysia\%20-\%20TC\%20Regs\%202015\%20-\% 20national.pdf [Accessed 5 Mar 2019].

28 Government of Malaysia. Control of tobacco product (Amendment) regulation, 2018. Available: https://www.tobaccocontrollaws.org/ files/live/Malaysia/Malaysia\%20-\%20TC\%20Amdt.\%20Regs\% 202018\%20-\%20national.pdf [Accessed 5 Mar 2019].

29 Lim KH, Mohd Fadhli MY, Rosnah R, et al. Evaluation of Effectiveness of Implementation of "Komuniti Sihat Perkasa Negara" (KOSPEN) Programme in Malaysia- Phase 1 Malaysia: Ministry of Health 2014.

30 Institute for Public Health. Report of the global adult tobacco survey (GATS). Malaysia 2011. Malaysia: Ministry of Health, 2012.

31 Bobo FT, Thanasekaran P, Joice AJR, et al. Susceptibility to cigarette smoking and associated factors among high school students in Western Ethiopia. BMC Res Notes 2018;11:626.

32 Bunnell RE, Agaku IT, Arrazola RA, et al. Intentions to smoke cigarettes among never-smoking us middle and high schoo electronic cigarette users: National youth tobacco survey, 20112013. Nicotine Tob Res 2015;17:228-35.

33 Barrington-Trimis JL, Berhane K, Unger JB, et al. The e-cigarette social environment, e-cigarette use, and susceptibility to cigarette smoking. Journal of Adolescent Health 2016;59:75-80.

34 Central of Disease Control and Prevention. Adolescent and school health, 2016. Available: https://www.cdc.gov/healthyyouth/data/yrbs/ questionnaires.htm [Accessed 16 Feb 2019].

35 WHO. Global youth tobacco survey, Thailand, 2015. Available: http:// www.searo.who.int/tobacco/surveillance/tha_gyts_report_2015.pdf [Accessed 20 Apr 2019]

36 Department of Statistic Malaysia. Population and housing census. Available: https://www.dosm.gov.my/v1/index.php? $r=$ column/cone\& menu_id=bDA2VkxRSU40STcxdkZ4OGJ0c1ZVdz09 [Accessed on 20 April 2019].

37 The nature and development trend of the National urban system. Available: http://archive.unu.edu/unupress/unupbooks/uu11ee/ uu11ee0l.htm [Accessed 20 Apr 2019].

38 Chen JC, Das B, Mead EL, et al. Flavored e-cigarette use and cigarette smoking susceptibility among youth. tobacco reg sci 2017;3:68-80.

39 Wills TA, Sargent JD, Knight R, et al. E-Cigarette use and willingness to smoke: a sample of adolescent non-smokers. Tob Control 2016;25:e52-9.

40 Haardörfer R, Cahn Z, Lewis M, et al. The advertising strategies of early e-cigarette brand leaders in the United States. Tob Regul Sci 2017;3:222-31.

41 Bruijnzeel AW. Reward processing and smoking. Nicotine Tob Res 2017;19:661-2.

42 Bell K, Keane H. All gates lead to smoking: The 'gateway theory', e-cigarettes and the remaking of nicotine. Soc Sci Med 2014;119:45-52.
43 Kandel D, Kandel E. The gateway hypothesis of substance abuse: developmental, biological and societal perspectives. Acta Paediatr 2015;104:130-7.

44 Lee AK. Pallipudi K English LM, Ramanandraibe N, Asma $\mathrm{S}$;Secondhand smoke exposure and susceptibility to initiating cigarette smoking among never-smoking students in selected African countries: Findings from the Global Youth Tobacco Survey. Prev Med 2016;91S:S2-8.

45 Russell K, Mclntire A, Nelson-Jonathan TM, et al. Secondhand smoke exposure and other correlates of susceptibility to smoking: a propensity score matching approach. Addict Behav 2015;48:36-43.

46 Masiero M, Lucchiari C, Pravettoni G. Personal fable: optimistic bias in cigarette smokers. Int J High Risk Behav Addict 2015;4:e20939.

47 World Health Organization. Tobacco smoke and involuntary smoking: summary of data reported and evaluation. Geneva: WHO, 2004.

48 Wilkinson AV, Waters AJ, Vasudevan V, et al. Correlates of susceptibility to smoking among Mexican origin youth residing in Houston, Texas: a cross-sectional analysis. BMC Public Health 2008;8:337

49 Minaker LM, Shuh A, Nguyen N, et al. Cigarette smoking susceptibility among youth alternate tobacco product users: implications of flavoured tobacco from a national cross-sectional Canadian sample (YSS 2012/2013). BMJ Open 2015;5:e009549.

50 Zhu C, Cai Y, Ma J, et al. Predictors of intention to smoke among junior high school students in Shanghai, China: an empirical test of the information-motivation-behavioral skills (IMB) model. PLoS One 2013;8:e80482

51 Spanopoulos D, Britton J, McNeill A, et al. Tobacco display and brand communication at the point of sale: implications for adolescent smoking behaviour. Tob Control 2014;23:64-9.

52 Paynter J, Edwards R, Schluter PJ, et al. Point of sale tobacco displays and smoking among 14-15 year olds in New Zealand: a cross-sectional study. Tob Control 2009;18:268-74.

53 Robinson JD, Drobes DJ, Brandon TH, et al. Evaluating point of sale tobacco marketing using behavioral laboratory methods. tobacco reg sci 2016;2:414-25.

54 Nuyts PAW, Kuipers MAG, Cakir A, et al. Visibility of tobacco products and advertisement at the point of sale: a systematic audit of retailers in Amsterdam. BMJ Open 2018;8:e022017.

55 Pollay RW. More than meets the eye: on the importance of retail cigarette merchandising. Tob Control 2007;16:270-4.

56 Sohn M, Jung M. Effect of viewing smoking scenes in motion pictures on subsequent smoking desire in Audiences in South Korea. JMIR Public Health Surveill 2017;3.

57 Mejia R, Pérez A, Peña L, et al. Smoking in movies and adolescent smoking initiation: a longitudinal study among Argentinian adolescents. J Pediatr 2017;180:222-8.

58 Bandura A. Social learning theory. New Jersey: Prentice-Hall, Inc, 1977.

59 Glanz K, Rimer BK, Lewis FM. Health Behavior and Health Education. Theory, Research and Practice. San Fransisco: Wiley \& Sons, 2002.

60 Bushman BJ, Huesmann LR, Short-term. Short-Term and long-term effects of violent media on aggression in children and adults. Arch Pediatr Adolesc Med 2006;160:348-52.

61 Barnett TA, Gauvin L, Lambert M, et al. The influence of school smoking policies on student tobacco use. Arch Pediatr Adolesc Med 2007;161:842-8.

62 Aryal UR, Petzold M, Bondjers G, et al. Correlates of smoking susceptibility among adolescents in a peri-urban area of Nepal: a population-based cross-sectional study in the JhaukhelDuwakot health demographic surveillance site. Glob Health Action 2014;7:24488.

63 Aryal UR, Bhatta DN. Perceived benefits and health risks of cigarette smoking among young adults: insights from a cross-sectional study. Tob Induc Dis 2015;13:22.

64 Ajzen I. From intentions to actions: A theory of planned behavior". In Kuhl J, Beckman J, eds. Action-control: From cognition to behavior. Heidelberg: Springer, 1985: 11-39.

65 Zawahir S, Omar M, Awang R, et al. Effectiveness of antismoking media messages and education among adolescents in Malaysia and Thailand: findings from the International tobacco control Southeast Asia project. Nicotine \& Tobacco Research 2013;15:482-91. 